\title{
Evaluar iniciativas de desarrollo comunitario desde la perspectiva de la innovación social. El caso de Gazteleku en el barrio de Rekalde (Bilbao)
}

\author{
Begoña Abad Miguélez* \\ Mikel Arriaga Landeta* \\ <mikel.arriaga@ehu.es>
}

\author{
Oihane García Santiago* \\ Javier González Burutxaga* \\ * Koheslan. Grupo de Estudios para la Cohesión Social. \\ Departamento de Sociología 2. Universidad del País Vasco (UPV/EHU)
}

\begin{abstract}
Artikulu hau Koheslan (Euskal Herriko Unibertsitatearen Gizarte Kohesiorako Ikasketa Taldea) eta Gaztelekurekin (Errekalde auzoko Komunitate Garapenerako Elkartearekin) batera izandako kolaborazio-esperientziaren fruitua da. Komunitate-garapena eta gizarte-kohesioaren gaiei buruzko interes komunari esker bion arteko elkartzea lehen ere ematen zen elkargune ezberdinetan. Behin batean Elkarteak bere ibilbidearen hausnarketa kritikoa egin nahi zuela adierazi zuen eta Ikasketa Taldeak gizarte-berrikuntza kontzeptua eta dialogoan oinarritutako metodologia eskaini zizkion gizarte-ekimen berritzaileen ebaluatze-eredu bezala.
\end{abstract}

\section{HITZ-GAKOAK:}

Komunitate-garapena, gizarte-berrikuntza, ebaluazio komunikatiboa, gizarte-kohesioa, gizarte eta kulturako animazioa, gizarte-sustapena.
Este artículo da cuenta de una experiencia de colaboración entre Koheslan (Grupo de Estudios para la Cohesión Social de la Universidad del País Vasco) y Gazteleku (Asociación de Desarrollo Comunitario del barrio de Rekalde, Bilbao). El interés común en el desarrollo comunitario y la cohesión social ha llevado a ambos a coincidir en espacios de encuentro. En ellos se ha expresado la voluntad de la asociación de abordar una reflexión crítica sobre sí misma que se significara como punto de inflexión para adecuar su intervención. El grupo de estudios ha ofrecido la perspectiva conceptual de la innovación social y la metodología comunicativa como bases para la evaluación de iniciativas de acción social.

\section{Palabras Claves:}

Desarrollo comunitario, innovación social, evaluación comunicativa, cohesión social, animación sociocultural, promoción social. 


\section{Planteamiento de estudio}

El estudio de caso al que nos vamos a referir se inserta en el debate en torno a dos aspectos controvertidos: los criterios de análisis y definición de las iniciativas socialmente innovadoras, y los criterios para evaluar sus logros y resultados. Vamos a argumentar la necesaria vinculación entre los dos extremos, siendo así que la propia definición operativa de la innovación social conlleva un replanteamiento de los modelos de evaluación, desde los modelos de carácter tecnoburocrático, en los que el enfoque socioeconómico prevalece, hacia modelos centrados en la evaluación de los efectos desde perspectivas cualitativas, en las que la mirada se dirige a los sujetos para visibilizar buenas prácticas y obtener conocimientos para la acción.

Por consiguiente, el estudio se aborda desde la perspectiva que proporciona el concepto de innovación social y se sirve de una estrategia investigadora de tipo comunicativo. Se trata de ir descubriendo -a través del diálogo- las claves que han permitido a Gazteleku mantener y acrecentar su actividad después de más de treinta años, para evaluar finalmente su presente y su futuro en el desarrollo comunitario local.

El primer objetivo del estudio es la generación de conocimiento acerca de lo que Gazteleku ha venido aportando al desarrollo comunitario en su entorno local, el barrio de Rekalde (Bilbao). Ello demanda acotar un espacio temporal que va desde su gestación a finales de los años setenta -como Comisión de Jóvenes de la Asociación de Familias de Rekaldeberri-, pasando por su transformación en asociación a primeros de los ochenta, hasta llegar a la realidad adulta actual.

Una vez cerrado el anterior, el estudio se abre a un segundo objetivo de actualización del conocimiento acerca de las necesidades de la población del barrio en el contexto actual de crisis socioeconómica, y a un tercer objetivo de evaluación de la actividad de la asociación desde el punto de vista de la innovación, es decir, de su capacidad de repensarse en orden a satisfacer nuevas necesidades individuales y colectivas.

\section{En el contexto de un barrio desfavorecido}

Comenzamos presentando el contexto en el que la iniciativa social Gazteleku prende y se desarrolla. Rekalde es un barrio desfavorecido, siempre lo ha sido. En ello han coincidido, en un primer ejercicio de campo, informadores relevantes del lugar (una mujer octogenaria, un antiguo párroco y exdirector de escuela en Rekaldeberri, un vecino de Uretamendi inmigrante en los años cincuenta, un miembro de la Comisión de Jóvenes de la antigua Asociación de Familias de Rekaldeberri y dos miembros de Gazteleku) reunidos con Koheslan al objeto de crear memoria significativa del Rekalde obrero e inmigrante de las décadas sesenta y setenta del pasado siglo. Un posterior repaso de documentación estadística nos
Gizarte-berrikuntzaren

kontzeptuak eskaintzen duen

ikuspegiarekin bat etorrita eta estrategia komunikatiboa erabiliz proposatu eta garatu da azterketa

ha permitido concretar más esa percepción de desfavorecimiento y configurar el mapa social del barrio en la actualidad.

Rekalde está situado en la vertiente sur de la periferia de Bilbao e incluye los enclaves de Uretamendi, Peñascal y Rekaldeberri, cada cual con subdivisiones en las que no entraremos. Los dos primeros son, a su vez, espacialmente periféricos a Rekaldeberri, y aunque cada cual goza de una marcada personalidad como barrio, la estrecha relación entre ellos es causa de que se denomine como barrio de Rekalde al conjunto de los tres.

Los tres enclaves tienen carácter obrero, viviendas pequeñas y diversidad cultural, aunque Rekaldeberri es el mayor de ellos y tiene más recursos municipales, que comparte con los otros dos. En Rekaldeberri se encuentran la oficina municipal del distrito, los servicios sociales de base, la biblioteca y el salón de actos, entre otros equipamientos.

El barrio de Rekalde está incluido administrativamente en el Distrito 7 de Bilbao, junto a otros barrios (Iralabarri y Amézola), e incluso presta al distrito su nombre de Rekalde. No obstante, en el estudio nos hemos centrado únicamente en el 'barrio', lugar al que se da forma sociohistórica a través de la memoria colectiva, un espacio ciertamente cambiante, pero identificable como común.

A principios de los años noventa, Rekalde se caracterizaba por albergar familias con muchas dificultades. En aquella época, gran parte del vecindario provenía de otras comunidades autónomas, principalmente de Galicia, Castilla-León, Extremadura y de Cantabria. Eran familias con bajo nivel de instrucción y renta, que iniciaban un nuevo proyecto familiar.

En 1991, los tres barrios tenían alta población infantojuvenil, lo que se vivía como un problema grave, pues las familias de estatus socioeconómico bajo tenían dificultades para cubrir las necesidades de sus menores. En muchos aspectos los niños y jóvenes del barrio partían en desventaja. Desde siempre Rekalde ha sido sensible a la cuestión educativa, así que diversas asociaciones se implicaron en pos de un mejor futuro para la infancia y la juventud del barrio. Entre esas asociaciones se encontraba Gazteleku.

A día de hoy, el Observatorio Urbano de Bilbao (Leonardo, 2012) constata que la población de Rekalde se percibe en peor situación que la mayoría de barrios de 
Bilbao en calidad de vida o sentimiento de bienestar general, en equipamientos, en clima de mayor tensión y sensación de inseguridad, y en predisposición a cambiar de residencia si se dieran las condiciones. Para 2012, la población infantojuvenil ha descendido considerablemente y el índice de vejez es prácticamente el doble. Por lógica, las tasas de dependencia han aumentado notablemente y la población es de bastante mayor edad que años atrás, aunque menos acentuadamente en Peñascal (Tabla 1).

Tabla 1. Indicadores demográficos estructurales. Rekalde y municipio de Bilbao, 2012

\begin{tabular}{l|c|c|c|c}
\cline { 2 - 5 } & Rekaldeberri & Uretamendi & Peñascal & Bilbao \\
\hline Índice de infancia & $12,9 \%$ & $12,1 \%$ & $13,7 \%$ & $12,1 \%$ \\
\hline $\begin{array}{l}\text { Índice de } \\
\text { juventud }\end{array}$ & $15,9 \%$ & $14,8 \%$ & $17,5 \%$ & $15,2 \%$ \\
\hline Índice de vejez & $22,8 \%$ & $22,8 \%$ & $16,7 \%$ & $22,4 \%$ \\
\hline $\begin{array}{l}\text { Tasa de } \\
\text { dependencia }\end{array}$ & $55,4 \%$ & $53,5 \%$ & $43,7 \%$ & $52,8 \%$ \\
\hline $\begin{array}{l}\text { Índice de } \\
\text { maternidad }\end{array}$ & $18,8 \%$ & $17,3 \%$ & $21,9 \%$ & $18,6 \%$ \\
\hline $\begin{array}{l}\text { Edad media } \\
\text { (años) }\end{array}$ & 45 & 44 & 41 & 45 \\
\hline
\end{tabular}

Fuente: Elaboración propia a partir de datos de Lan Ekintza.

La composición de Rekalde también está cambiando (Tabla 2). La base principal de la población sigue siendo autóctona o proveniente de otras comunidades autónomas, pero desde 2000 las personas originarias de otros países han ido en aumento, mientras que las autóctonas y las de origen inmigrante ya asentadas han ido envejeciendo. Las nuevas familias llegan con el propósito de comenzar una nueva vida. Principalmente son sudamericanas y africanas, aunque también hay un porcentaje menor proveniente del resto de Europa.

\section{Erronka handia zen haurren} eta gazteen etorkizuna. Hargatik, elkarte askok bere egin zuen haurren eta gazteen egoera hobetzeko borroka, Gazteleku horien artean

El nuevo fenómeno de migración está ayudando a rejuvenecer poco a poco la población. Los nuevos pobladores y las nuevas pobladoras son muy importantes para el rejuvenecimiento de estos tres barrios. Tienen entre 20 y 40 años, apenas hay mayores de 50, y abundan los niños y las niñas.

Los datos de la oferta educativa en el Distrito 7 revelan que los centros escolares se encuentran con una nueva realidad. La media de extranjeros sobre la población total es de un $11,5 \%$ mientras que la proporción de alumnado extranjero sobre alumnado total en educación primaria y secundaria es de más del doble (Gráfico 1).

Tabla 2. Población nacida en el extranjero, por barrio y lugar de nacimiento. Rekalde, 2010

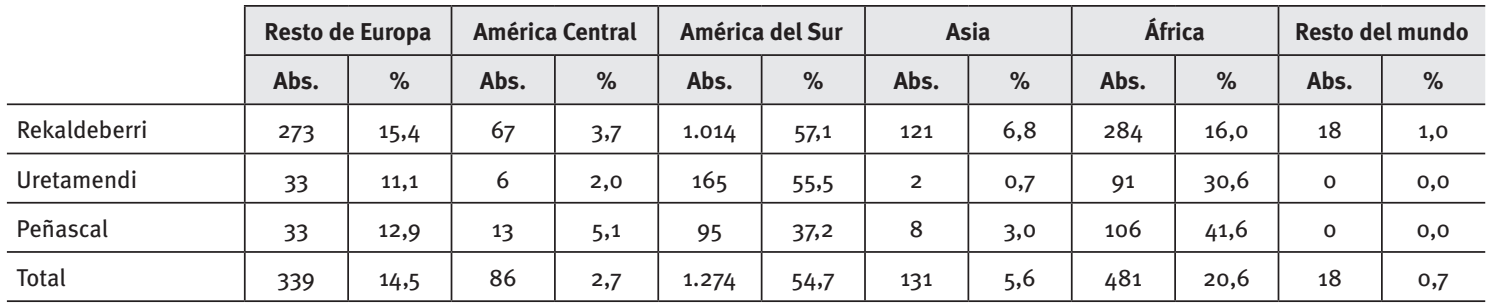

Fuente: Elaboración propia a partir de Bilbao en Cifras (Ayuntamiento de Bilbao).

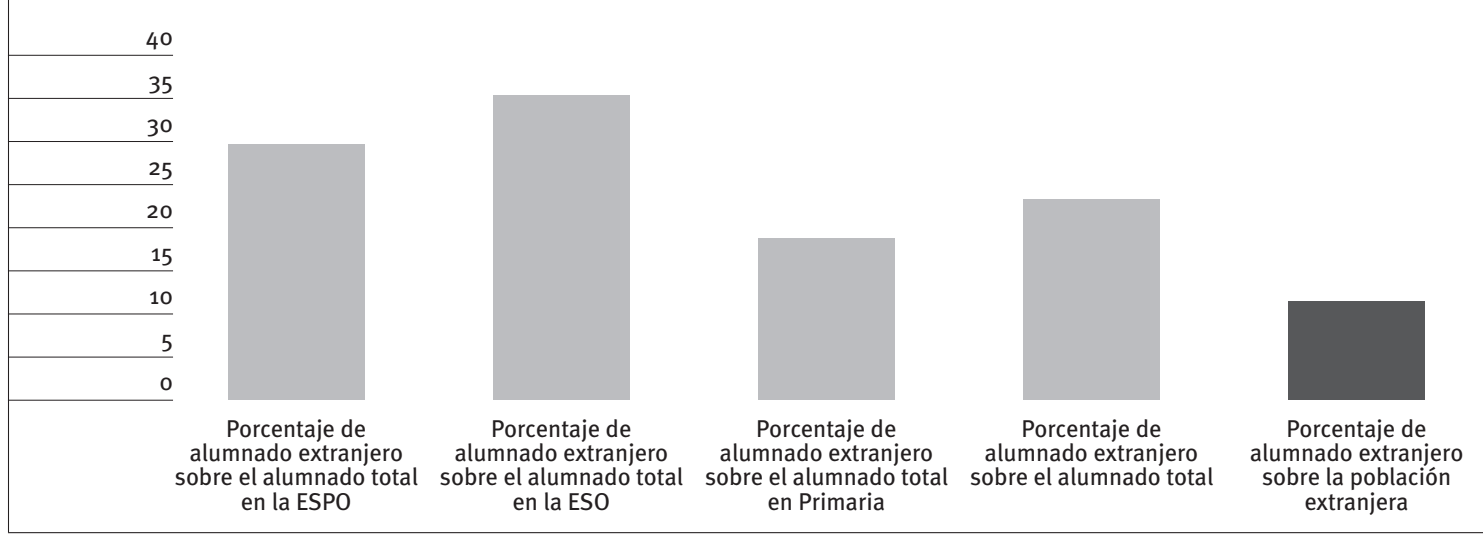

Fuente: Elaboración propia a partir de datos de Departamento de Educación del Gobierno Vasco. 


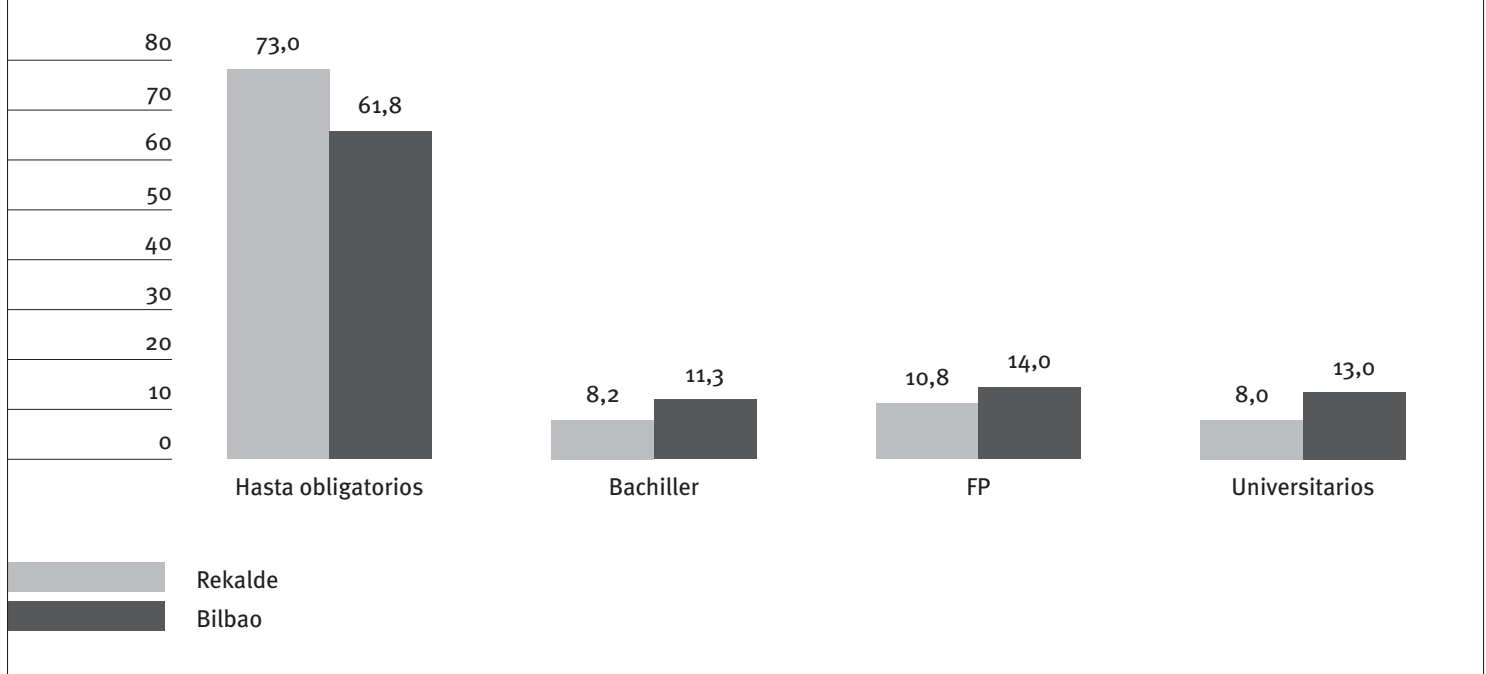

Fuente: Elaboración propia a partir de datos de Lanbide.

Esta población infantil se encuentra desfavorecida. Sus familias se instalan en barrios que carecen de actividad económica relevante y tienen un nivel de instrucción más bajo y una situación laboral más precaria. Ni que decir tiene que la posibilidad de fracaso escolar en un sistema educativo afectado por los recortes es además una dificultad importante en su trayectoria. Así, el grado de vulnerabilidad ante situaciones de riesgo -por ejemplo, de desempleoes bastante mayor que en el municipio.

La población con escaso nivel formativo tiene menos posibilidades de encontrar empleo, por lo que en Rekalde, sobre todo en los barrios de Peñascal y Uretamendi, el riesgo es alto. En estos dos, las rentas familiares son las más bajas de todo el municipio y llevan, entre otras cosas, a que los menores y las menores crezcan en un entorno difícil, con problemas económicos familiares, con un futuro laboral incierto y sin un respaldo familiar y social suficientemente sólido.

En definitiva, tanto a partir de datos subjetivos como objetivos se puede afirmar con rigor que Rekaldeberri, Uretamendi y Peñascal, sobre todo estos dos últimos, son barrios desfavorecidos en los que el riesgo de caer en situación de exclusión social es mayor que en la media de Bilbao.

\section{Gizarte-egoera ahulean}

Errekalde, hala auzokideen pertzepziotik nola datu estatistikoetan oinarritutako diagnostikotik

\section{Gazteleku dentro de la dinámica histórico-social del barrio}

En el anterior mapa histórico-social, los miembros de Gazteleku se autoperciben en sintonía con los valores de solidaridad y autogestión que caracterizaron los procesos transformadores del barrio en el pasado, tanto aquellos que son memoria recibida de sus mayores -la construcción de viviendas de los años sesenta y setenta en Uretamendi y Peñascal- como los que son memoria vivida por ellos mismos - la apertura de los primeros centros de enseñanza media y FP entre finales de los setenta y primeros de los ochenta, la regeneración urbana de la zona centro de Rekaldeberri de comienzos a mediados de los ochenta, y las ocupaciones de viviendas oficiales tras las inundaciones de 1983 (Asociación de Familias de Rekaldeberri, 2010)-.

Si hablamos de destinatarios de su acción, la población infantojuvenil y sus familias han sido siempre prioridad, particularmente las personas y los colectivos más desfavorecidos socialmente. Tras un exhaustivo repaso documental de las prácticas que la asociación ha llevado y lleva a cabo, una decena de miembros y exmiembros de aquélla (de diferentes edades, áreas de actuación y grado de vinculación) informaron y opinaron sobre ello, refiriendo dichas prácticas a los siguientes ámbitos:

- Animación sociocultural, dirigida a la educación de menores en tiempo libre: busca sensibilizar a la población infantojuvenil sobre el consumo crítico, el respeto y la defensa medioambiental, la igualdad de género o el uso el euskera, entre otras cuestiones.

- Promoción social: se dirige, desde la educación social, a personas y familias en riesgo de exclusión, a las que proporciona contextos relacionales favorables a la inclusión social. 
- Participación y desarrollo comunitario: impulsa o apoya iniciativas vecinales junto a otras agencias sociales en el campo educativo, de la salud, sociourbanístico o deportivo.

En los tres ámbitos, se desarrollan programas específicos en los que intervienen 33 personas profesionales contratadas, 68 voluntarias y 26 colaboradoras puntuales; todas ellas interactúan con las personas participantes/beneficiarias de las actividades, que ascienden a 720 por semana.

\section{Bizi-egoera larrian diren haurrak, gazteak eta beraien familiak dira Gaztelekuren akzio sozialaren xedea, eta jarduteko ildo ezberdinak garatu ditu urteetan zehar}

\section{La evaluación de iniciativas sociales desde la perspectiva de la innovación social. Criterios generales y propuestas analíticas}

El concepto de innovación social está adquiriendo predicamento en el ámbito de las políticas públicas, como puede observarse en la estrategia de desarrollo europea para el 2020 (Bureau of European Policy Advisers, 2009), y en el ámbito académico, luego del Mayo del 68 y las revoluciones de los años setenta. En Les innovations sociales, Chambon et al. (1982) relacionan la innovación social con los cambios sociales, interesándose especialmente en los mecanismos por los que se acelera la innovación social en época de crisis, satisfaciendo las necesidades específicas de las comunidades gracias a iniciativas colectivas asentadas en procesos conscientes de crecimiento, movilización y aprendizaje.

A partir de los años ochenta, se produce un interés creciente por las ideologías, formas organizativas y estrategias de los movimientos sociales (Staggenborg, 1989; McCarthy, 1996). En los años noventa, numerosos trabajos dirigen su mirada a las innovaciones en los servicios destinados a las personas y al propio sistema de bienestar (Baldock y Evers, 1992; Esping-Andersen, 1996; Vaillancourt, 2002). Ello ha generado una vasta literatura sobre innovaciones, acompañada de la proliferación de centros y plataformas creadas con el fin de potenciar la investigación y el intercambio de conocimiento.

No obstante, el creciente debate e interés por el concepto no ha resuelto la ambigüedad intrínseca a su definición. Baste señalar que los trabajos sobre innovación social se pueden distinguir en dos grandes bloques: por un lado, aquellos que centran su análisis en la innovación social como respuesta a problemas y condiciones sociales (Mulgan, 2006 y 2007); y por otro, los que analizan la innovación social en el contexto de la gobernanza y el desarrollo democrático tanto territorial como organizacional (Healey 2004; Moulaert et al., 2010; MacCallum et al., 2009; Moulaert y Nussbaumer, 2008).

Más allá de los debates, lo que nos interesa resaltar aquí es el potencial analítico del concepto. Su aplicación operativa nos la ofrece el modelo utilizado por González, Moulaert y Martinelli (2010), el modelo ALMOLIN (Alternative Model of Local Innovation), que responde a tres preguntas básicas: ¿por qué?, ¿cómo? y ¿qué? En el estudio que nos ocupa, nos hemos servido de este modelo como plantilla para el acercamiento al campo y para la gestión de la información. De este modo, hemos convertido las preguntas claves del modelo ALMOLIN en criterios de diagnóstico y autorreflexión. Así, el diagnóstico de la iniciativa (de la asociación Gazteleku, en nuestro caso) desde la perspectiva de la innovación social se basa en tres criterios:

- El primero responde a la originalidad de la idea, al motivo impulsor o al porqué desencadenante del surgimiento de la iniciativa y, al mismo tiempo, a sus objetivos y propósito. En definitiva, se trata de la misión y señas de identidad de la asociación frente a la exclusión social y la privación en un contexto o medio social concreto. En este punto, las fortalezas se identifican como la capacidad de mantener vivos los objetivos y valores propios, mientras que las debilidades se entienden como lagunas o conflictos en la transmisión de las señas de identidad.

- El segundo criterio responde a la creatividad en el proceso o al cómo. La creatividad y capacidad innovadora en el proceso refleja la existencia de una 'organización que aprende', una organización que, sin dejar de ser lo que la define, se adapta al entorno y se visualiza en relación con él, cambiando y adaptándose a sus exigencias, movilizando recursos humanos o financieros. Las fortalezas y debilidades innovadoras se relacionan, en este punto, con la capacidad no sólo de gestionar e implementar de una forma más o menos novedosa recursos materiales y humanos, sino también con la capacidad para desplegar las habilidades que están detrás de esa capacidad de gestión, entre ellas, el despliegue de un pensamiento asociativo, la actitud receptiva y abierta hacia el entorno, el establecimiento de redes, la capacidad de experimentar y repetir, y la capacidad de aprender de los errores.

- El tercer criterio responde al resultado innovador o al qué. La capacidad de innovar se traduce en la creación de valor añadido en contenidos (la satisfacción de las necesidades individuales y colectivas), en procesos (generar nuevas oportunidades y contextos de relación social, especialmente en lo que se refiere a la gobernanza) y 
en capacitación o empoderamiento (incrementar la capacidad sociopolítica y el acceso a recursos necesarios, realzando los derechos a la satisfacción de las necesidades humanas y a la participación, en especial en el caso de grupos sociales en situación de vulnerabilidad). Las debilidades, por su parte, vienen asociadas a la dificultad de definir y gestionar con claridad las metas y objetivos a corto y medio/largo plazo, así como con la dificultad para concretar el éxito o alcance de estos logros.

Acercándonos a una definición escueta que recoja el sentir de los criterios antedichos, nos hacemos solidarios de la siguiente:

Las innovaciones sociales tienen como objetivo primario generar un valor social añadido para el conjunto de la sociedad -o algún sector desfavorecido de ésta-, y no sólo privado o individual. En consecuencia, la evaluación de la innovación no puede realizarse sobre criterios económicos y de productividad -como en su sentido tecnológico-, sino sobre una acumulación inmaterial que corresponde al dominio de las personas y las colectividades (Bouchard, 2006: 10-12).

Desgranada la definición en tres propuestas analíticas útiles al procedimiento evaluador, consideramos que una iniciativa socialmente innovadora se caracteriza por:

- Ser original en sus objetivos. Orientada a satisfacer necesidades, individuales y colectivas mal cubiertas bien porque 'todavía no', bien porque 'nunca más' son o serán percibidas -ellas mismas y los colectivos a quienes afectan- como importantes por el mercado o por el Estado (Subirats, 2004).

- Estar dotada de espíritu creativo. Ser una organización que aprende, que adapta su funcionamiento a nuevos requerimientos coyunturales, sin dejar por ello de ser aquello que la constituye, esto es, una asociación "orientada a generar oportunidades, a crear contextos de relación social y a tejer redes de solidaridad de los grupos sociales en situación de vulnerabilidad" (Zinnbauer, 2007: 16).

- Ser generadora de valor añadido en la comunidad. En el diseño y desarrollo de su acción, busca favorecer un aumento en la capacidad de las personas afectadas, ofreciéndoles "contextos de relación con un alto nivel de participación donde ellas mismas puedan participar en el proceso de creación e implementación de los planes de
Una vez propuestos los criterios generales para la elaboración de nuevos modelos de seguimiento y evaluación de resultados, así como las tres propuestas o categorías para el análisis concreto, queremos traer a consideración la virtualidad del modelo ALMOLIN, de un lado, para posibilitar la reflexión de los actores desde sus propias prácticas y experiencias y, de otro, para sustentar el proceso de generación de conocimiento en la colaboración, la comunicación y la cooperación.

\section{Gizarte-berrikuntzen helburua da balio gehigarri bat sortzea, gizarte osoarentzat edo egoera ahulean dagoen gizarte talde batentzat, ez soilik balio pribatu edo banakakoa}

\section{Estrategia para el estudio y evaluación de la iniciativa Gazteleku}

Así, partiendo del concepto guía de innovación social y desde una perspectiva dialógica en evaluación, realizamos un ejercicio de diálogo, con la finalidad de confrontar a los propios agentes activos de la asociación -a su experiencia y a sus prácticas-con las bases conceptuales y premisas de definición de una iniciativa considerada socialmente innovadora, ordenando la información en los tres ámbitos de preocupación recogidos en el modelo (por qué, cómo y qué).

Se entrevistó en profundidad a diez personas que atendían a características diversas (estamentales y de intervención) que pudieran representar al universo humano interno de la asociación. En concreto, participaron en las entrevistas: un antiguo miembro activo, una voluntaria, miembro del Consejo Asociativo, un trabajador del área de Dirección-Gestión (coordinador), una trabajadora del área de Animación Sociocultural, un voluntario de la misma área, un trabajador del área de Desventaja Social, un extrabajador de la misma área, una trabajadora del área de Participación Comunitaria, una voluntaria de la misma área y una antigua colaboradora.

Posteriormente, abordamos un diálogo intersubjetivo, entendido como un inicio de reflexión colectiva sobre algunas cuestiones significativas verbalizadas en las entrevistas. Lo fundamental reside en el hecho de que miembros de los diferentes estamentos de la asociación han puesto en común y dialogado acerca de algunas de sus preocupaciones desde diferentes perspectivas. Al objeto, se reunieron las trece personas intervinientes en las entrevistas (las diez entrevistadas y las tres entrevistadoras), en un encuentro que tuvo tres momentos. En el primero, una miembro de Koheslan expuso tres citas literales entresacadas de las entrevistas que expresan originalidad, creatividad y resultado positivo de la iniciativa Gazteleku y sobre las que existe un acuerdo unánime. En un segundo momento, los participantes 
se reunieron en subgrupos de cuatro personas (todos ellos con representación de Gazteleku y Koheslan) $\mathrm{y}$, siguiendo el mismo procedimiento, dialogaron en torno a ideas que no habían alcanzado el mismo nivel de unanimidad. En el tercer momento, los participantes volvieron a reunirse para poner en común sus reflexiones sin ánimo de agotar sus posibilidades.

\section{Evaluación de la iniciativa Gazteleku desde la perspectiva de la innovación social}

La reflexión sobre los resultados de los diversos ejercicios llevados a cabo a lo largo del proceso investigador nos ha llevado finalmente a la evaluación de Gazteleku como iniciativa socialmente innovadora, atendiendo a las tres propuestas analíticas referidas en el epígrafe anterior.

- Originalidad de la idea: la iniciativa surge en respuesta a necesidades del barrio y de sus gentes. Una línea de atención de la asociación está orientada a la población infantojuvenil; otra mira a la población del barrio en su conjunto, interesándose en tejer red con otras entidades para revindicar mejoras y construir comunidad.

- Creatividad en el proceso: a lo largo del tiempo ha mostrado flexibilidad para adaptar su funcionamiento a requerimientos coyunturales e institucionales. El desarrollo de esta capacidad adaptativa no se ha producido fuera de control, sino bajo exigencias interpuestas por la propia asociación, velando así para que los objetivos educativos y autogestionarios no se desvirtúen, es decir, privilegiando la perspectiva de generación de capital social en el barrio.

- Resultado de la acción: el resultado de la acción desplegada por Gazteleku no es evaluable en términos cuantitativos. Si bien éstos avalan la asociación, el trabajo educativo tiene efectos que sólo son reconocibles con el paso del tiempo y, a menudo, en forma de expresiones de reconocimiento comunitario (las más) y de reconocimiento institucional (las menos). De ambas expresiones hay sobrado testimonio.

En resumen, el trabajo educativo que desarrolla la asociación no se caracteriza por producir efectos inmediatos o éxitos espectaculares. Dicho en lenguaje metafórico, la acción que despliega tiene más de lluvia fina que de tormenta con aparato. La claridad de objetivos, la persistencia en el tiempo y la atención a la comunidad, a la vez que a las personas dentro de ella, hablan de un colectivo innovador, con presente y con futuro.

Destacado lo anterior, la evaluación también alerta sobre obstáculos a la innovación a los que se enfrenta toda entidad -también Gazteleku-que defiende la gestión propia de sus proyectos, a la vez que reclama ayuda institucional pública o privada para llevarlos a cabo. Como señala Comeau (2004), el despliegue de las virtudes de la innovación democrática local suele hallar dificultades en la práctica cotidiana, pues se enfrenta al problema del poder. El peligro es que los proyectos devengan en servicios, productos o prácticas ‘de parcheo’. La elección adecuada en cada momento exige tensión -reforzamiento del hábito de hacer y hacerse preguntas sobre el statu quo propio y sobre el del entorno político/administrativo-, a fin de evitar que la exigencia externa de resultados a corto plazo rompa la coherencia del hacer educativo propio. También se ha de tener siempre presente que buenas prácticas no es lo mismo que prácticas innovadoras socialmente, es decir, que "el mero desarrollo institucional o el perfeccionamiento de una práctica ya existente en su eficiencia o en su eficacia no es, por sí misma, una innovación social” (Morales, 2009: 158).

Ideiaren originaltasunak, prozesuan dagoen sormenak eta pertsonen eta taldeen mende dagoen metatze materiagabeak gizarte-ekimen berritzaile gisa definitzen dute Gazteleku

Esta experiencia de estudio/evaluación, llevada a cabo por un grupo universitario de estudios sociales en colaboración con una asociación de desarrollo local, pretende inaugurar un proceso evaluador en la propia entidad, constituyéndose como buena base para generar nuevas iniciativas socialmente innovadoras. Dicho de otra forma, la experiencia no ha buscado concluir, sino constituirse en punto de partida de una práctica innovadora habitual, propia de una organización que aprende.

Así, como consecuencia directa de este proceso, la asociación de desarrollo comunitario ha abierto un seminario de reflexión interna, que implica a todos los estamentos y áreas, para adaptar su intervención en tres direcciones:

- Reforzar su trabajo específico dirigido a las personas en situaciones socioeconómicas más difíciles, tomando en cuenta que la capacitación y el empoderamiento de las propias personas debe constituir un objetivo irrenunciable. Solidaridad y participación son los valores que se han de movilizar.

- Fortalecerse en valores para abordar la intervención más cualificadamente. El qué, el cómo y el para qué de las nuevas iniciativas solidarias pueden ser buen objeto para una reflexión en la que se eleve el diálogo desde una concepción instrumental a sustancia misma de la vida asociativa. 
- Promover en el barrio de Rekalde encuentros de puesta en común de iniciativas transformadoras, con el doble objetivo de identificar nuevas necesidades y de consensuar guías de acción acordes a la nueva situación de crisis socioeconómica.

\section{Referencias bibliográficas}

ASOCIACIÓN DE FAMILIAS DE REKALDEBERRI (2010): Rekaldeberri, la trama de un barrio, Bilbao, Asociación de Familias de Rekaldeberri.

BALDOCK, J.; EVERS, A. (1992): "Innovations in care for the elderly: The cutting-edge of change for social welfare systems. Examples from Sweden, the Netherlands and the United Kingdom", Ageing and Society, vol. 12, no 3, págs. 289-312.

BOUCHARD, M. J. (2006): L'innovation sociale en économie sociale, colección: Recherche, $\mathrm{n}$ - R/2006-01, Chaire de Recherche du Canada en Économie Sociale.

BUREAU OF EUROPEAN POLICY ADVISERS (2009): Social Innovation as Part of the Europe 2020 Strategy. Executive Summary, Bruselas, Comisión Europea.

CHAMBON, J. L.; ALIX, D.; y DAVEVEY, J. M. (1982): Les innovations sociales, colección: Que Sais-Je?, París, Presses Universitaires de France.

COMEAU, Y. (2004): Les contributions des sociologies de l'innovation à l'étude du changement social, serie: CRISES Collection Études Théoriques, no ETo418, Centre de Recherche sur les Innovation Sociales, págs. 29-39.

ESPING-ANDERSEN, G. (ed.) (1996): Welfare States in Transition. National Adaptations in Global Economies, Londres, Sage.

GONZÁLEZ, S.; MOULAERT, F.; y MARTINELLI, F. (2010): "ALMOLIN. How to analyse social innovation at the local level?", en MOULAERT, F. et al. (eds.), Can Neighbourhoods Save the City? Community Development and Social Innovation, Londres, Routledge, págs. 49-67.

LEONARDO, J. (dir.) (2012): Observatorio Urbano de Bilbao. III Informe. Marzo-abril 2012, Bilbao, Ayuntamiento de Bilbao [<http://www.bilbao. net/observatoriobarrios/informe/informe percepcion_2012.pdf〉].

MCCALLUM, D. et al. (2009) Social Innovation and Territorial Development, Surrey, Ashgate.

MCCARTHY, J. D. (1996) “Constraints and opportunities in adopting, adapting and inventing", en MCADAM, D.; MCCARTHY, J. D.; y ZALD, M. N. (eds.), Comparative Perspectives on Social Movements, Nueva York, Cambridge University Press.

MORALES, A. C. (2009): “Innovación social: un ámbito de interés para los servicios sociales", Zerbitzuan,
El grupo universitario de estudios sociales, por su parte, ha visto enriquecida su comprensión acerca de las iniciativas de desarrollo comunitario, un conocimiento que podrá trasladar al ámbito de discusión y referencia académico, investigador y político, trascendiendo el marco de lo local y facilitando ejercicios de comparación e intercambio con iniciativas similares. no 45, págs. 151-178 [<http://www.zerbitzuan. net/documentos/zerbitzuan/12.pdf`].

MOULAERT, F.; y NUSSBAUMER, J. (2008): La logique sociale du développement territorial, Québec, Presses de l'Université du Québec.

MOULAERT, F. et al. (eds.) (2010): Can Neighbourhoods Save the City? Community Development and Social Innovation, Londres, Routledge.

SEN, A. (2000): Desarrollo como libertad, Madrid, Planeta.

STAGGENBORG, S. (1989): "Stability and innovation in the women's movement: A comparison of two movement organizations", en Social Problems, vol. $36, \mathrm{n}^{0} \mathbf{1}$.

SUBIRATS, J. (dir.) (2004): Pobreza y exclusión social. Un análisis de la realidad española y europea, colección: Estudios Sociales, nํ16, Barcelona, Fundació La Caixa [rhttp:// obrasocial.lacaixa.es/StaticFiles/StaticFiles/ a84f7102892efo10VgnVCM1000000e8cf10a RCRD/es/es16_esp.pdf)].

VAILLANCOURT, Y. (2002) “Le modèle québécois de politiques sociales et ses interfaces avec l'union sociale canadienne", Enjeux Publics, vol. $3, \mathrm{n} \div 2$.

ZINNBAUER, D. (2007): What can Social Capital and ICT do for Inclusion?, Luxemburgo, Oficina de Publicaciones de la Unión Europea [〈http://ftp.jrc.es/EURdoc/eur22673en.pdf〉].

\section{Bases de datos utilizadas}

Centro de Documentación del Ayuntamiento de Bilbao, Bilbao en Cifras: 〈http://www.bilbao.net/ cs/Satellite?cid=3000038782\&language $=$ es\&pagename $=$ Bilbaonet $\% 2 \mathrm{FPage} \% 2 \mathrm{FB}$ IO_listadoPublicaciones〉.

Departamento de Educación del Gobierno Vasco: 〈http:// www.hezkuntza.ejgv.euskadi.net/r43-2591/es〉.

Lan Ekintza: 〈http://www.bilbao.net/cs/ Satellite?pagename $=$ LanEkintza/Page $/$ LKZ_PTPortada\&site $=$ LanEkintza\&c $=$ Page\&loca le $=3000001694$ '.

Lanbide: 〈http://www.lanbide.net〉. 